\title{
The Role of Cyclic Adenosine Monophosphate in Adrenergic Effects on Ventricular Vulnerability to Fibrillation in the Isolated Perfused Rat Heart
}

\author{
W. F. Lubbe, Th. Podzuweit, P. S. Daries, and L. H. Opie, Medical Research \\ Council Ischemic Heart Disease Research Unit, Department of Medicine, \\ University of Cape Town and Groote Schuur Hospital, Observatory, 7925, \\ Cape, Republic of South Africa
}

\begin{abstract}
A в S T RACT The relation between myocardial tissue cyclic AMP (cAMP) and the vulnerability to ventricular fibrillation was assessed in the isolated perfused rat heart by measurement of ventricular fibrillation threshold (VFT) and vulnerable period duration (VP). Exogenous dibutyryl cyclic AMP (DBcAMP) reduced VFT and increased VP by a concentration-related action whereas exogenous cAMP did not. Theophylline $(1.0 \mathrm{mmol} / \mathrm{liter})$ increased the tissue content of cAMP by $58 \%(P<0.001)$ and caused a leftward shift in the concentration-response curve to DBcAMP. An effect of cAMP on VFT and VP could be shown in the presence of phosphodiesterase inhibition by theophylline. $\beta$-1-Adrenergic receptor blockade with atenolol did not alter the concentration-response curve for VFT when DBcAMP was administered. Epinephrine (100 nmol/liter to $l$ $\mu \mathrm{mol} /$ liter) also increased vulnerability to $\mathrm{VF}$; this effect was accompanied by a concentration-related increase in tissue cAMP, but inconsistent changes in tissue ATP, phosphocreatine and potassium. The concentration-response curve of VFT to epinephrine was shifted leftward by theophylline and rightward by atenolol.

The increases in vulnerability to fibrillation in the isolated perfused rat heart, in response to DBcAMP, theophylline or epinephrine, could be related more closely to changes of tissue cAMP than to effects on tissue high energy phosphates or potassium. The effect of epinephrine and theophylline on vulnerability to ventricular fibrillation is mediated via alterations in the intracellular level of cAMP in the isolated perfused rat heart.
\end{abstract}

Received for publication on 1 August 1977 and in revised form 16 December 1977.

\section{INTRODUCTION}

Primary ventricular fibrillation in the early phase of myocardial infarction is thought to occur because of the combination of electrical instability and an altered myocardial vulnerability. Vulnerability to ventricular fibrillation increases within minutes of coronary artery occlusion in the dog (1-3). The catecholamines may play an important role in the mediation of changes in ventricular vulnerability. Increased release of catecholamines in the setting of acute myocardial ischemia is associated with ventricular arrhythmias in dogs (4) and in patients (5) while $\beta$-adrenergic receptor blockade (6) and sympathetic denervation (7) exert a protective effect against ventricular arrhythmias in the dog with coronary occlusion.

A possible biochemical basis for the development of early ventricular fibrillation after coronary artery ligation in baboons was suggested by the finding that the content of cyclic AMP in ischemic myocardium rose 5-20 min before the onset of ventricular fibrillation (8). Administration of dibutyryl cyclic AMP reduced the ventricular fibrillation threshold and increased the duration of the vulnerable period in the isolated perfused rat heart (9). A cAMP-linked action whereby catecholamines cause alterations in ventricular vulnerability to fibrillation has been suggested (10).

The present study was designed to explore in detail the relationship between myocardial tissue cAMP content and ventricular vulnerability in the isolated perfused rat heart, a model devoid of anesthetic and extrinsic neurogenic influences. The pharmacological characteristics of the action whereby exogenously administered DBcAMP lowers the ventricular fibrillation threshold were defined and compared with the actions elicited by increasing intracellular cAMP endog- 
enously, either by stimulation with epinephrine or by inhibition of phosphodiesterase with theophylline. The effects of theophylline and epinephrine on the ventricular fibrillation threshold and the vulnerable period duration correlated best with the influence of these agents on tissue cAMP but not with changes in levels of high energy phosphate compounds nor of tissue potassium.

\section{METHODS}

Ventricular fibrillation threshold $(\mathrm{VFT})^{1}$ and vulnerable period duration (VP) were estimated in the isolated perfused rat heart as described (11). Male Long-Evans rats, $180-250 \mathrm{~g}$, were anesthetized with ether and given $100 \mathrm{U}$ heparin i.v. Hearts (wet weight $0.9-1.1 \mathrm{~g}$ ), with atria intact, were rapidly excised, arrested in ice-cold perfusate solution and mounted on a Langendorff apparatus. Perfusion was retrograde from a reservoir at $100 \mathrm{~cm} \mathrm{H}_{2} \mathrm{O}$ pressure using Krebs-Henseleit buffer $\left(\mathrm{K}^{+}=5.9 \mathrm{meq} / \mathrm{liter}\right)$ equilibrated with $95 \% \mathrm{O}_{2}$ and $5 \% \mathrm{CO}_{2}$, at $37^{\circ} \mathrm{C}$ to maintain $\mathrm{pH}$ at 7.4 (substrate $11 \mathrm{mmol} /$ liter glucose).

Continuous electrocardiograms were recorded from one electrode on the metal aortic perfusion cannula, and a $2-\mathrm{cm}$ platinum wire (36 standard wire gauge) soldered to thin flexible insulated copper wire and inserted superficially into the free wall of the right ventricle. Two similar platinum wire electrodes were inserted for electrical stimulation (11). The cathodal electrode was placed adjacent to the atrioventricular groove in the ventricular muscle while the anode was placed at the apex. Anodal stimulation with square-wave pulses of $2 \mathrm{~ms}$ duration were generated by a Grass S 88 physiological stimulator (Grass Instruments Co., Quincy, Mass.). A beat-to-beat trigger was provided by a synchronized output pulse from the ETD channel of an EFM DR 8 recorder (Electronics for Medicine, Inc., White Plains, N. Y.). The stimulating impulse was passed through a Grass constantcurrent unit (Grass Instrument $\mathrm{Co}$.) to a Grass stimulus isolation unit (Grass Instrument Co.) to ensure square-wave impuses with current as constant as possible in the face of possible variations in electrode contact resistance. Recordings were obtained on a Philips Analog 7 Instrumentation magnetic tape recording unit (Philips (Nederland), Bosdijk Geboun, Einthoven, Netherlands). Playback was on to either a Tektronix Type 549 Storage Oscilloscope (Tektronix, Inc., Beaverton, Oreg.) at $500 \mathrm{~mm} / \mathrm{s}$ for accurate measurement of time intervals or on to an Elema Mingograph ink-writing recorder (Elema-Schönomder, Solna, Sweden) at the paper speed of $25 \mathrm{~mm} / \mathrm{s}$ for definition of arrhythmias. VF was defined as a repetitive arrhythmia with irregular and varying morphology which persisted for more than six cycles (11).

The VFT was estimated using an initial current of $7.5 \mathrm{~mA}$ and systematic stimulation at $2.5 \mathrm{~ms}$ intervals across the total duration of the $\mathrm{T}$ wave, applying two impulses at each point. The current was increased by $2.5 \mathrm{~mA} / \mathrm{sweep}$ until $\mathrm{VF}$ was obtained. The early limit of the vulnerable period was defined more accurately by retracing to the previous 5 $\mathrm{ms}$ division and proceeding at $1 \mathrm{~ms}$ intervals until VF was again obtained. The reverse procedure was used to define

${ }^{1}$ Abbreviations used in this paper: ATP, adenosine triphosphate; cAMP, cyclic adenosine $3^{\prime} 5^{\prime}$ monophosphate; DBCAMP, dibutyryl cyclic AMP; EC, effective concentration; $\mathrm{VF}(\mathrm{T})$, ventricular fibrillation (threshold); VP, vulnerable period duration. the later limit of the vulnerable period. The current was then reduced by $0.5-\mathrm{mA}$ steps and the limits of the vulnerable period at the threshold current accurately defined. Vulnerable period duration at threshold current was usually 1-2 $\mathrm{ms}$ and for purposes of comparison the duration $1 \mathrm{~mA}$ above the threshold current was measured. VF invariably terminated spontaneously after 5-10 s in this preparation; when it persisted with the interventions used in this study electrical defibrillation was attempted using a current of 10 $\mathrm{mA}$ and up to five isolated shocks but, if this procedure failed, perfusate at $4^{\circ} \mathrm{C}$ was gently syringed over the heart until arrest occurred. A few seconds after such cold arrest, electrical activity returned in sinus rhythm. A period of 2 min was then allowed for full recovery before stimulation was resumed.

Observations of heart rate and coronary flow were obtained at the beginning and end of each period, the former by measurement of the intervals between complexes recorded on the storage oscilloscope, the latter by collection of the coronary sinus effluent for $30 \mathrm{~s}$ into a graduated measuring cylinder.

Chemicals. $\quad \mathrm{N}^{6}, 2^{\prime}$-O-dibutyryl adenosine $3^{\prime}, 5^{\prime}$-monophosphate (DBcAMP) (98\% purity) and $3^{\prime}, 5^{\prime}$ cyclic adenosine monophosphate (cAMP) as the sodium salt (98\% purity) were obtained from the Sigma Chemical Company, St. Louis, Mo.

Epinephrine hydrochloride was obtained as pure crystalline powder from Petersen Manufacturing Chemists, Epping Industria, Cape Town.

Theophylline (1,3-dimethylxanthine) was obtained as the pure crystalline salt from Merck AG, Darmstadt, West Germany.

Atenolol (ICI 66082, 4-[2-hydroxy-3-isopropyl-aminopropoxy]phenylacetamide) was supplied as the pure powder by Imperior Chemical Industries, Pharmaceutical Research Division, Macclesfield, England.

\section{Experimental procedure}

After the initial determination of the VFT and the VP duration, the following interventions were used:

Control experiments. Perfusion was switched from the perfusate reservoir to the alternate reservoir with identical perfusate and without the addition of any agents. After a perfusion period of $15 \mathrm{~min}, \mathrm{VFT}$ and VP were re-estimated. The hearts were then freeze-clamped for tissue analyses. The possible contribution of the high heart rates achieved with theophylline and epinephrine to the changes in VFT and VP duration was assessed by pacing 15 hearts at rates of 300,350 , and $400 / \mathrm{min}$. Atrial pacing was achieved by insertion of a stimulating electrode into the myocardium of the right atrium and applying impulses of $3-5$ volts and $0.2 \mathrm{~ms}$ duration using the second channel of the S88 stimulator as an impulse generator. Pacing was continued for $10 \mathrm{~min}$ at each heart rate before estimation of VFT and VP.

Infusion of DBCAMP or of $c A M P$. Solutions were prepared to deliver amounts of nucleotide varying between 0.5 and $20 \mu \mathrm{mol} / \mathrm{min}$ and were delivered at a rate of $0.5-1.0$ $\mathrm{ml} / \mathrm{min}$ by a Braun infusion pump (B. Braun Apparatebau, Melsungen, Germany) to a 20 -ml capacity bubble trap immediately above the aortic perfusion cannula. Both nucleotides were dissolved in perfusate and infusions were administered for $15 \mathrm{~min}$ before the repeat estimation of the VFT and VP duration. Coronary flow and heart rate were estimated at the beginning and end of infusion periods and the terminal value of coronary flow was used to calculate the concentration of nucleotide reaching the heart.

Theophylline administration. Theophylline was dissolved in the perfusate solution by gentle heating and continuous 
stirring, and added to the second perfusate reservoir. Hearts were exposed to theophylline for $10 \mathrm{~min}$ before the repeat estimation of VFT and VP was commenced. When theophylline or atenolol was added to DBCAMP or cAMP, a third period of measurement of VFT and VP was undertaken while care was taken to ensure uninterrupted infusion of DBcAMP or CAMP.

Epinephrine administration. Epinephrine was dissolved in the perfusate and administered by infusion pump to the bubble trap above the aortic cannula, delivering a volume of $0.5-1 \mathrm{ml} / \mathrm{min}$. Solutions were prepared freshly for each experiment and even though experiments were performed in relative darkness, the infusion syringe was wrapped in aluminum foil to minimize possible oxidation of the epinephrine.

In experiments involving the combined administration of epinephrine with theophylline or atenolol, the epinephrine was always administered by infusion whereas the other agents were dissolved in the perfusate in the second reservoir.

$\beta$-Adrenergic blockade. Blockade of the $\beta$-1-adrenergic receptors was obtained using the selective blocking agent, atenolol. A concentration of $38 \mu \mathrm{mol} / \mathrm{liter}$ inhibited the chronotropic effect of $1.0 \mu \mathrm{mol} / \mathrm{liter}$ epinephrine but had only a slight negative chronotropic action and by itself did not alter VFT or VP.

Tissue analyses. Hearts were rapidly frozen at the end of the experiments by clamping with Wollenberger tongs precooled in liquid nitrogen (12). The frozen hearts were powdered in a percussion mortar kept under liquid nitrogen. 50-100 mg Aliquots of tissue were then extracted into $1 \mathrm{ml}$ ice-cold 5\% (W/W) perchloric acid by using an UltraTurrax blender (Janke \& Kunkel, Staufen/Breisgau, West Germany). The extracts were centrifuged for $15 \mathrm{~min}$ at $15,000 \mathrm{~g}$ and the supernate neutralized with a mixture of four parts $40 \%$ (W/W) $\mathrm{KOH}$ saturated with $\mathrm{KCl}$ and six parts $0.2 \mathrm{M}$ Tris- $\mathrm{HCl}$ buffer, $\mathrm{pH}$ 7.5. The perchlorate precipitate was removed by centrifugation to yield a clear extract and the metabolites measured directly in these extracts. Tissue ATP and phosphocreatine were measured fluorometrically by the hexokinase/glucose-6-phosphate dehydrogenase reaction. Tissue cAMP was measured by the protein binding assay of Brown et al. (13). The cAMP assay was verified by use of internal standards and by proof of zero interference by cAMPfree extracts (pretreated with phosphodiesterase). Aliquots of powdered heart tissue were used to determine the dry/wet weight ratio which was used to calculate the fresh weight (fresh weight $=$ dry weight times five, see Opie et al. [14]).

Tissue potassium content was estimated on extracts of the powdered hearts by flame photometry with lithium as an internal standard.

\section{Statistical procedures}

Results are expressed as mean $\pm \mathrm{SEM}$ for number of observations. $P$ values were obtained from Student's $t$ test, unpaired or paired as appropriate, with the two-tailed test as allowance for unequal variances. ${ }^{2}$

\section{RESULTS}

\section{Base-line and control experiment observations}

In 70 experiments the mean base-line value of VFT was $7.5 \pm 0.4 \mathrm{~mA}$; the $\mathrm{VP}$ duration $1 \mathrm{~mA}$ above thres-

${ }^{2}$ Diem K., and C. Lentner, editors. 1970. Scientific Tables. Ciba-Geigy Limited, Basel Switzerland. hold current was $3.5 \pm 0.2 \mathrm{~ms}$; heart rate was $262 \pm 4$ beats $/ \mathrm{min}$ and coronary flow rate was $10.6 \pm 0.4 \mathrm{ml} / \mathrm{min}$.

In the series of 11 control experiments in which VFT was re-estimated 15 min after switching perfusion from the first to the second perfusate reservoir, no changes in VFT, VP duration, heart rate, or coronary flow rate were observed (Table 1). The hearts used in the control experiments were assayed biochemically after freeze-clamping. The mean tissue values for 11 hearts were: cAMP, $0.48 \pm 0.01 \mathrm{nmol} / \mathrm{g}$ fresh wt; ATP, $3.9 \pm 0.01 \mu \mathrm{mol} / \mathrm{g}$ fresh wt; phosphocreatine, $4.0 \pm 0.2$ $\mu \mathrm{mol} / \mathrm{g}$ fresh $\mathrm{wt}$; and tissue $\mathrm{K}^{+}, 87.8 \pm 3.2 \mathrm{meq} / \mathrm{kg}$ fresh wt.

In 15 hearts in which the heart rate was increased by atrial pacing, VFT was $8.5 \pm 0.8,7.8 \pm 1.1$, and 7.1 $\pm 1.2 \mathrm{~mA}$ at rates of 300,350 , and $400 / \mathrm{min}$ respectively. The vulnerable period duration was likewise not increased by merely increasing the heart rate to these levels.

\section{Effects of exogenously administered DBcAMP and cAMP (alone and together with theophylline and atenolol)}

$D B c A M P$. The influence of DBcAMP on VFT was determined by the concentration of nucleotide in the perfusate (Figs. 1 and 2). With concentrations in the perfusate below $100 \mu \mathrm{mol} / \mathrm{liter}$, responses were inconsistent, some hearts showing an increase in VFT, others showing either no change or a decrease (Fig. 1). With concentrations of $100 \mu \mathrm{mol} /$ liter and higher, a uniform decrease in VFT occurred (Fig. 1). The increases in VFT seen with the lower concentrations were also in every instance converted into a substantial decrease when theophylline was added to DBCAMP. The alteration in concentration-response relationships for DBCAMP produced by addition of theophylline $(1.0 \mathrm{mmol} / \mathrm{liter})$ and atenolol $(38 \mu \mathrm{mol} /$ liter) is shown in Fig. 2A. Between 8 and 15 hearts were studied at each concentration of the nucleotide. The concentration of DBCAMP that caused a $50 \%$ reduction in VFT (effective concentration, $\mathrm{EC}_{50}$ ) was 160 $\mu \mathrm{mol} /$ liter. Changes in vulnerable period duration in response to DBcAMP occurred in parallel with the changes in VFT. Marked widening of VP occurred with higher concentrations of DBcAMP, particularly in combination with theophylline. With concentration of DBcAMP of $600 \mu \mathrm{mol} / \mathrm{liter}, \mathrm{VP}$ duration reached 10,12 , and $15 \mathrm{~ms}$ in three hearts in which this measurement was obtainable at a current $1 \mathrm{~mA}$ about VFT. Persistence of refractory fibrillation in the presence of DBCAMP in concentrations above $250 \mu \mathrm{mol} / \mathrm{liter}$ or in combination with theophylline often rendered the definition of VP duration impossible.

The effects of $1.0 \mathrm{mmol} / \mathrm{liter}$ theophylline by itself on the rat hearts are included in Table I. This con- 
TABLE I

Observations on Control Hearts and during Interventions that Increase Tissue cAMP Content

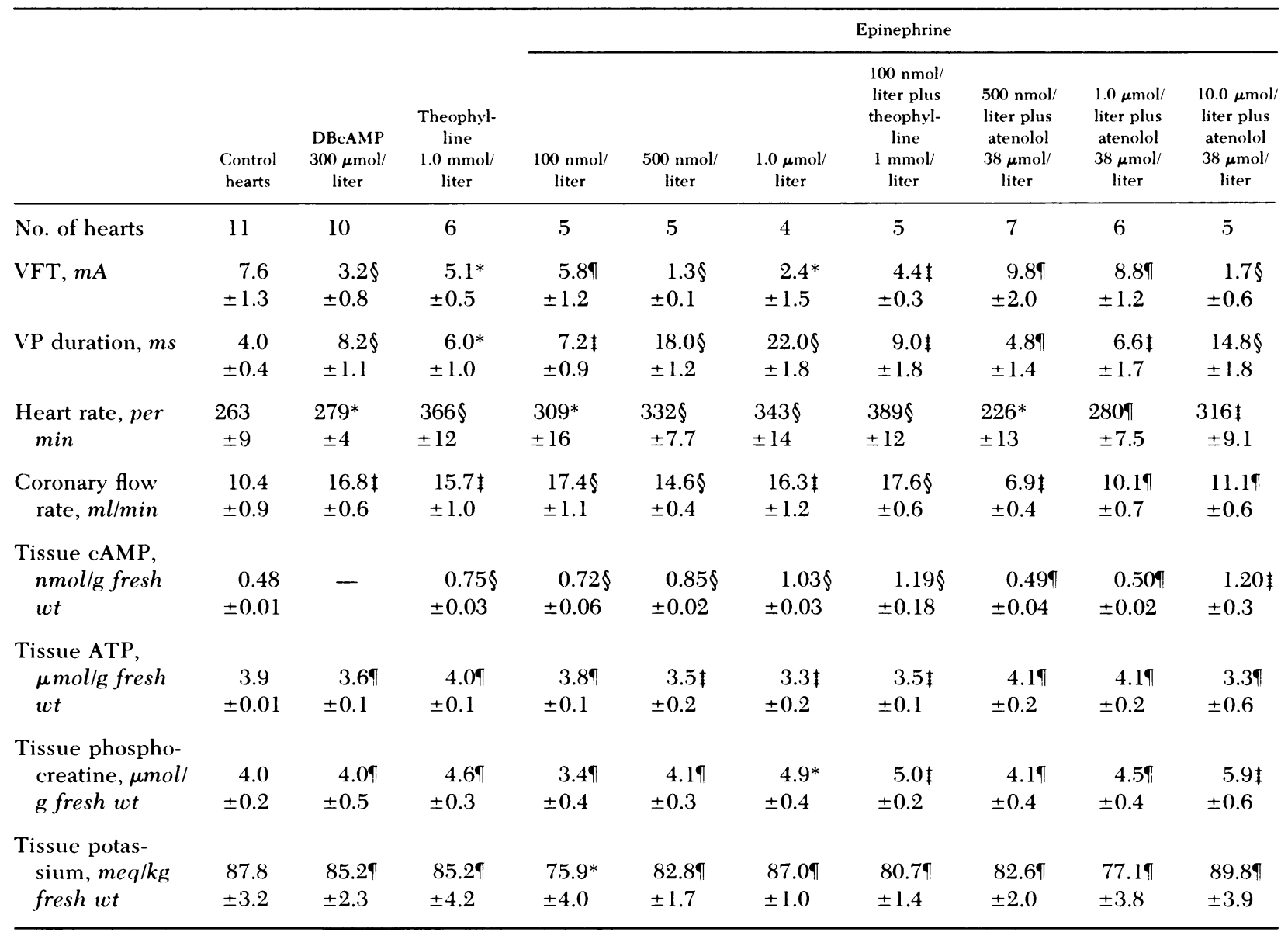

Only observations during administration of agonists that show typical changes or changes at end of spectra of responses are included. For full concentration-response relationships see Figs. 1 and 3 . The concentration of DBcAMP represents a mean concentration in a series of hearts in which definition of VP duration and complete biochemical analysis were possible (range 200-600 $\mu \mathrm{mol} / \mathrm{liter}$ ).

$P$ values relate to comparison with control hearts.

$* P<0.05$.

$\ddagger P<0.01$.

$\S P<0.001$.

I $P>0.05,<0.10$.

centration of theophylline increased heart rate by $40 \%$ and coronary flow rate by $56 \%$ of base-line values. The VFT was reduced by $27 \%(P<0.05)$ and VP duration was increased by $50 \%(P<0.05)$. These changes were accompanied by a highly significant increase in tissue cAMP $(58 \%, P<0.001)$, but no alterations in tissue content of ATP, phosphocreatine or potassium. Atenolol, $38 \mu \mathrm{mol} / \mathrm{liter}$, produced no alteration in VFT or VP duration, but reduced heart rate to $240 \pm 7$ beats $/ \mathrm{min}$ and coronary flow rate to $7.8 \pm 0.4$ $\mathrm{ml} / \mathrm{min}$ (30 experiments). These changes were significant at the level of $P<0.05$.
Theophylline $1.0 \mathrm{mmol} /$ liter when added to DBcAMP caused a highly significant leftward shift of the concentration-response curve for VFT whereas $\beta$-1-receptor blockade with atenolol did not produce any effect (Fig. 2A). The $\mathrm{EC}_{50}$ for DBcAMP in the presence of theophylline was $<35 \mu \mathrm{mol} / \mathrm{liter}$, the lowest concentration of DBcAMP studied in this series. In the presence of atenolol the $\mathrm{EC}_{50}$ remained unaltered at $160 \mu \mathrm{mol} /$ liter.

A significant increase in heart rate was caused by concentrations of DBCAMP of $250 \mu \mathrm{mol} / \mathrm{liter}$ or higher. With a DBcAMP concentration of $250 \mu \mathrm{mol} / \mathrm{liter}$ the 


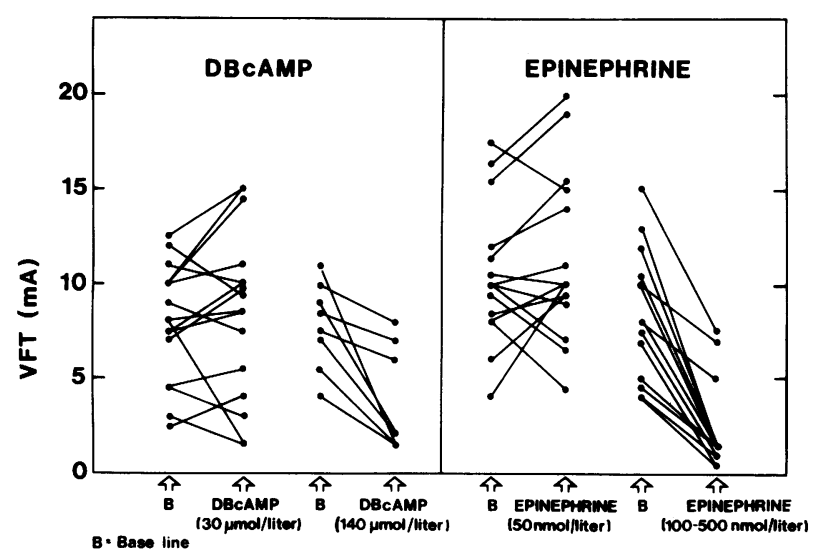

FIGURE 1 Inconsistent responses of VFT to low concentrations of DBcAMP (30 $\mu \mathrm{mol} / \mathrm{liter})$ and epinephrine (50 $\mathrm{nmol} /$ liter) showing elevation, no change or reduction of VFT in individual hearts studied. The uniform reductions of VFT obtained in all hearts studied at higher concentrations of DBCAMP and epinephrine are indicated.

heart rate in eight hearts was $283 \pm 8(P<0.01)$; with a concentration of $550 \mu \mathrm{mol} / \mathrm{liter}$ a further increase to $311 \pm 17(P<0.01, n=$ eight hearts $)$ occurred. The stimulatory effect of DBcAMP on coronary flow rate was evident with concentrations of $30 \mu \mathrm{mol} / \mathrm{liter}$ at which coronary flow rate was increased to $14.3 \pm 0.8$ $\mathrm{ml} / \mathrm{min}(P<0.01, n=10$ hearts $)$. The maximum increase in coronary flow rate occurred with a DBcAMP concentration of $550 \mu \mathrm{mol} /$ liter when $20.1 \pm 1.3 \mathrm{ml} / \mathrm{min}$ was reached $(P<0.001, n=$ eight hearts). When theophylline $1.0 \mathrm{mmol} / \mathrm{liter}$ was added to the perfusate together with DBcAMP, heart rate and coronary flow rate values were greatly augmented. With a DBcAMP concentration of $60 \mu \mathrm{mol} / \mathrm{liter}$, heart rate was increased to $438 \pm 16$ beats $/ \mathrm{min}(P<0.001, n=10)$ by the addition of theophylline. This value is significantly greater $(P<0.005)$ than the value obtained with theophylline alone $(366 \pm 12$ beats $/ \mathrm{min})$. With concentrations of DBcAMP of 140,250 , and $550 \mu \mathrm{mol} / \mathrm{liter}$, the values obtained with added theophylline were $417 \pm 12(P$ $<0.01), 404 \pm 17(P<0.05)$, and $393 \pm 10 \quad(P<0.05)$ beats/min respectively. At all levels of DBcAMP $>60$ $\mu \mathrm{mol} / \mathrm{liter}$ the increase in heart rate was therefore greater than could be attributed to the effect of theophylline alone. Likewise, with respect to coronary flow rate, a significant increase greater than that attributable to theophylline could be demonstrated. At a DBcAMP concentration of $30 \mu \mathrm{mol} / \mathrm{liter}$, together with theophylline, the coronary flow rate was 17.6 $\pm 0.8 \mathrm{ml} / \mathrm{min}$ which was significantly greater than the coronary flow rate obtained with theophylline alone, $15.7 \pm 1.0 \quad(P<0.01)$. The maximum coronary flow rate in the presence of theophylline was obtained with a DBcAMP concentration of $250 \mu \mathrm{mol} / \mathrm{liter}$, when a value of $20.5 \pm 1.2 \mathrm{ml} / \mathrm{min}$ was obtained.
Atenolol did not inhibit the increase in coronary flow rate or heart rate caused by DBcAMP.

Tissue cAMP measurements were not attempted in hearts infused with DBcAMP because of the difficulty in separating intra- and extracellular cAMP. However, DBcAMP in a concentration reducing VFT by $60 \%$ did not cause changes in tissue ATP, phosphocreatine or potassium (Table 1).

cAMP. When cAMP was infused, no reduction in VFT could be demonstrated even with perfusate concentrations of $600 \mu \mathrm{mol} / \mathrm{liter}$ (Fig. 2B). In combination with theophylline $(1.0 \mathrm{mmol} / \mathrm{liter}) \mathrm{a}$ decrease in VFT greater than that attributable to the theophylline alone, occurred at concentrations of cAMP $>150$ $\mu \mathrm{mol} / \mathrm{liter}$. The $\mathrm{EC}_{50}$ for cAMP in the presence of theophylline was $70 \mu \mathrm{mol} /$ liter. VP duration likewise remained unaffected during administration of cAMP by itself, but was increased when theophylline was added. These observations suggest a low intracellular penetration of cAMP, but its action on VFT and VP become evident when its breakdown is inhibited by theophylline.

Heart rate was decreased when cAMP was infused, reaching a $30 \%$ reduction at the highest concentration studied ( $600 \mu \mathrm{mol} / \mathrm{liter}$ ); despite this, the coronary flow rate was greatly increased, reaching $15.8 \pm 0.7$ $\mathrm{ml} / \mathrm{min}$ at the lowest concentration of cAMP studied (60 $\mu \mathrm{mol} /$ liter). There was no augmentation of the response in coronary flow rate to cAMP when theophylline was added. The responses of heart rate when theophylline was added to cAMP could be attributed to the theophylline.

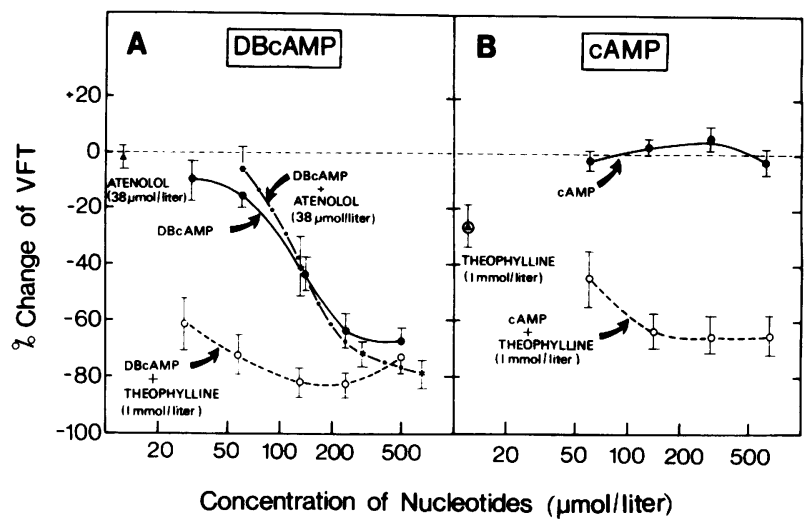

FIgURE 2 Concentration-response relationships plotted on a semilog scale for alterations in VFT produced by incremental concentrations of DBcAMP (A) and cAMP (B). Between 10 and 15 hearts were studied to obtain each point which is plotted as the mean $( \pm$ SEM). The effects of added theophylline $(1.0 \mathrm{mmol} / \mathrm{liter})$ and the $\beta$-1-adrenergic blocking agent, atenolol (38 $\mu \mathrm{mol} / \mathrm{liter})$ on the concentration-response curves is shown. The responses to theophylline (A) and atenolol (A) administered in the same concentration in the absence of DBcAMP and cAMP are indicated. 
Effects of administration of epinephrine alone and together with theophylline or atenolol (Table I, Figs. 1 and 3)

Administration of epinephrine produced changes in VFT, VP, heart rate, and coronary flow rate that resembled the effects of DBcAMP. However, with a perfusate epinephrine concentration of $50 \mathrm{nmol} /$ liter the tissue cAMP rose but VFT did not fall. At low concentrations of epinephrine, as with DBcAMP, an inconsistent response in VFT was seen; a uniform reduction in VFT and increase in VP duration occurred with higher concentrations (Fig. 1) or when theophylline $(1.0 \mathrm{mmol} / \mathrm{liter})$ was added to the epinephrine. An augmentation of the reduction in VFT by theophylline was clearly evident with concentrations of epinephrine up to $100 \mathrm{nmol} /$ liter (Fig. 3). In the presence of atenolol a decrease in VFT was encountered only with concentrations of epinephrine $>1 \mu \mathrm{mol} / \mathrm{liter}$.

Epinephrine caused concentration-dependent increases in heart rate and coronary flow rate; these effects were potentiated by the addition of $1 \mathrm{mmol} /$ liter theophylline at low concentrations of epinephrine $(<100 \mathrm{nmol} /$ liter $)$ whereas at higher concentrations the response curves coincided. Atenolol inhibited the responses in heart rate and coronary flow rate to epinephrine. Coronary flow rate was markedly reduced by the presence of atenolol together with epinephrine. A reduced coronary flow was found even at a concentration of epinephrine of $10 \mu \mathrm{mol} / \mathrm{liter}$ at which an increase in heart rate became evident (in the presence of $38 \mu \mathrm{mol} /$ liter atenolol).

The alterations in tissue levels of cAMP, ATP, and phosphocreatine are shown in Fig. 3 and Table I. Tissue ATP was reduced by epinephrine $100 \mathrm{nmol} /$ liter together with theophylline $1.0 \mathrm{mmol} /$ liter. In the presence of atenolol, epinephrine did not reduce tissue ATP. Tissue phosphocreatine was increased by the same levels of epinephrine that reduced tissue ATP. The most consistent changes were seen in tissue cAMP and the changes mirrored the alterations in VFT produced by the various interventions. Large reductions of VFT were accompanied by large increases of tissue cAMP as shown in Fig. 3. Small elevations of tissue cAMP, as with epinephrine in low concentrations or in the presence of atenolol, were not accompanied by reductions in VFT. As the epinephrine concentration was increased, a clear reduction in VFT was obtained when tissue cAMP increased further. Small changes in tissue phosphocreatine did not coincide with changes in VFT as did the changes in cAMP. Changes in tissue potassium were inconsistent and large changes in VFT were seen unaccompanied by changes in tissue potassium.

The findings in the presence of atenolol suggest

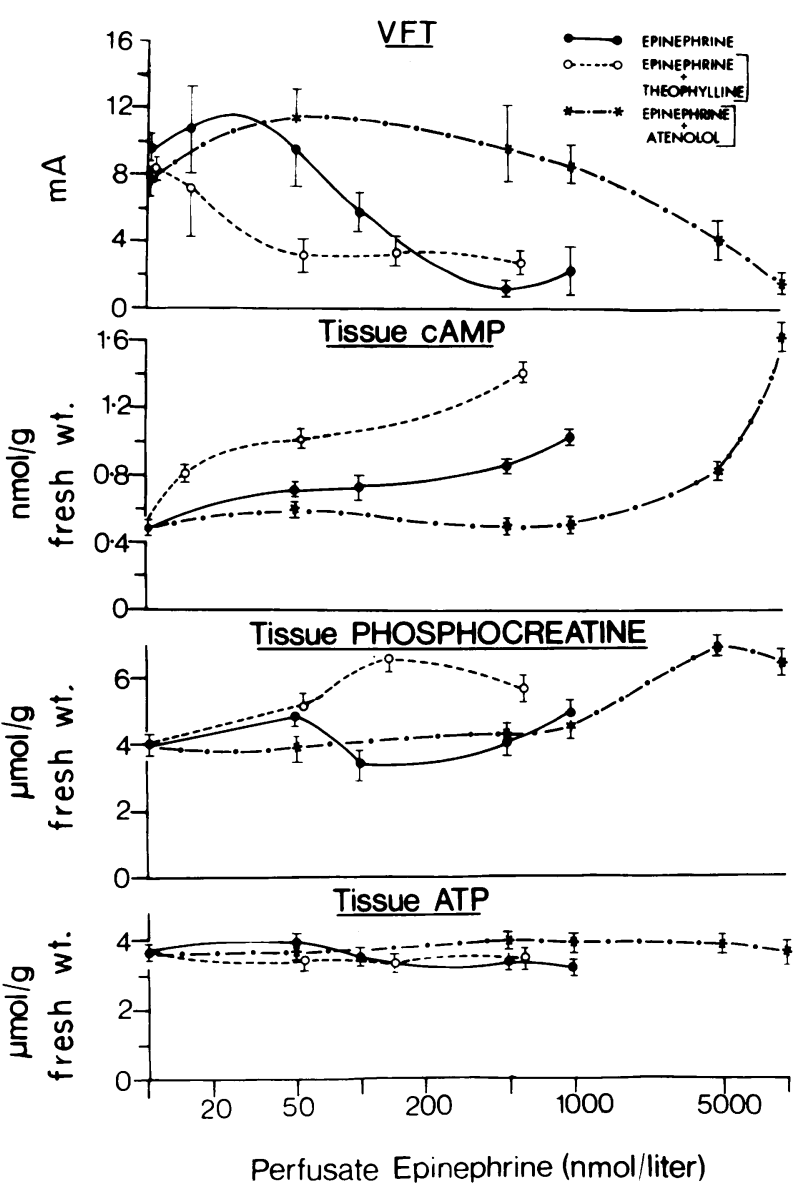

FIGURE 3 Concentration-response relationships plotted on semilog scale for VFT, tissue cAMP, and high energy phosphates in response to epinephrine. Each point indicates mean $( \pm$ SEM) for 6-10 hearts studied. The response curve of VFT to epinephrine coincides with an increase in tissue cAMP, but not changes in tissue phosphocreatine or tissue ATP. The curve was shifted to the left by theophylline 1 $\mathrm{mmol} /$ liter with higher levels of tissue CAMP achieved and elevation of tissue phosphocreatine, but no changes in tissue ATP. Atenolol, the $\beta$-l-adrenergic blocking agent shifted the VFT curve upwards and to the right; an increase in tissue CAMP was not seen until the reduction in VFT occurred, tissue phosphocreatine was increased at this stage, but tissue ATP remained unaltered.

that epinephrine therefore exerts its effect of lowering VFT via the $\beta$-1-receptor. Addition of theophylline to epinephrine caused exaggeration of effects on VFT and on tissue cAMP. The ability of the hearts to maintain high energy phosphate concentrations in the presence of these interventions indicate that the effects of epinephrine on vulnerability were not related to metabolic deterioration of the hearts.

\section{Spontaneously occurring VF}

Spontaneous ectopic ventricular rhythms have not been encountered in our series of more than 400 
experiments in the isolated perfused rat heart. In the present study spontaneous arrhythmias, usually selflimited atrial and ventricular tachycardia were encountered during infusion of DBCAMP and epinephrine in 18 hearts. Persistence of VF in the presence of added DBcAMP, epinephrine and theophylline rendered definition of VP duration impossible, except in a few experiments. During the combined administration of theophylline with DBcAMP $500 \mu \mathrm{mol} / \mathrm{liter}, 4$ of 10 hearts showed spontaneous $\mathrm{VF}$, while three other hearts had spontaneous ventricular premature extrasystoles or ectopic atrial tachycardia. During the combined administration of epinephrine and theophylline one heart was freeze-clamped $6 \mathrm{~s}$ after the onset of spontaneous VF. The tissue cAMP level obtained was $5.3 \mathrm{nmol}-\mathrm{g}$ fresh wt; tissue ATP was reduced to 2.6 $\mu \mathrm{mol} / \mathrm{g}$ fresh wt, but this may have been related to the $6 \mathrm{~s}$ duration of VF. Phosphocreatine was relatively well-maintained at $3.7 \mu \mathrm{mol} / \mathrm{g}$ fresh wt. The unstable electrical status and final persistence of spontaneous $\mathrm{VF}$ in this heart are shown in Fig. 4.

\section{DISCUSSION}

Perfusate cAMP and ventricular vulnerability. We previously found that ventricular vulnerability to fibrillation could be increased by the administration of exogenous DBcAMP to the isolated perfused rat heart (9), and showed that the effects of DBcAMP on ventricular vulnerability could not be related to the butyric acid released by the intracellular deacylation of DBcAMP. We now examine the relation between tissue cAMP changes and the VFT and VP. The sigmoid form of the concentration-response curve

(EPINEPHRINE $100 \mathrm{nmol} / \mathrm{liter}+$ THEOPHYLLINE $1.0 \mathrm{mmol} /$ liter )
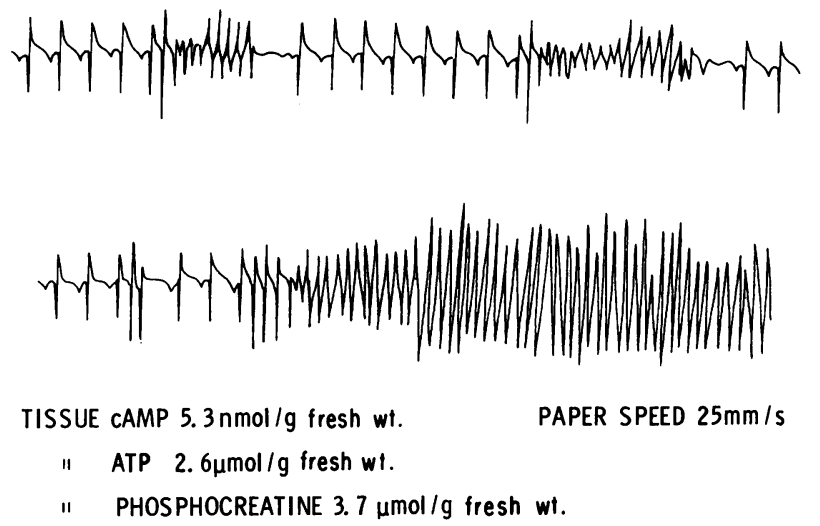

FIGURE 4 Recurrent and finally persistent VF occurring spontaneously in a rat heart subjected to stimulation with epinephrine $(100 \mathrm{nmol} /$ liter $)$ and theophylline $(1.0 \mathrm{mmol} /$ liter). The tissue levels of cAMP, ATP and phosphocreatine obtained when the heart was clamped $6 \mathrm{~s}$ after the onset of persistent VF are indicated. whereby cAMP acts on the VFT and VP suggests an agonistic rather than a permissive action. Because this action can be readily elicited by DBcAMP which crosses the cell membrane more readily than does cAMP (15), which penetrates cell membranes poorly, an intracellular site of action is likely. Further evidence for an intracellular site of action is provided by the effect of theophylline which increases cAMP intracellularly by inhibition of phosphodiesterase; it lowered VFT synergistically with DBcAMP to increase vulnerability whereas by itself it caused a reduction in VFT when tissue cAMP was increased. The demonstration that exogenously administered cAMP could exert an action similar to that of DBCAMP in the presence of theophylline suggests that small amounts of cAMP can penetrate the cell membranes to accumulate intracellularly and exert an action on vulnerability when its breakdown is prevented during phosphodiesterase inhibition.

A clear dissociation could be shown between the effects of cAMP on coronary flow rate and on VFT; the former effect was found at low concentrations of cAMP and presumably did not require myocardial cell penetration, which appeared to be obligatory for effects on VFT.

The effect of DBcAMP on ventricular vulnerability was not related to alterations in heart rate and was furthermore unaffected by atenolol, a $\beta$-1-selective adrenergic blocking agent which acts at a membrane level (16). This suggests that the action demonstrated for DBcAMP is independent of the $\beta$-1-receptor situated at the cell membrane, and is not mediated by locally released catecholamines. Stimulation with incremental concentrations of epinephrine however elicits an agonistic action qualitatively similar to that of DBcAMP; this action is inhibited competitively by atenolol which displaces the concentration-response curve to the right. Atenolol, while inhibiting the reduction of VFT in response to epinephrine also prevented an increase of tissue cAMP.

Correlation of changes in ventricular vulnerability with changes in tissue metabolism. Analysis of these isolated rat hearts subjected to stimulation with DBcAMP, theophylline, and epinephrine showed that the effects of these agonists on vulnerability to fibrillation were not accompanied by metabolic deterioration of the hearts, as assessed by measurement of tissue ATP or phosphocreatine content, but closely followed changes in tissue cAMP. Although a small elevation of tissue phosphocreatine could be shown in epinephrine-perfused hearts, it did not occur in hearts perfused with DBcAMP or theophylline. Alterations in tissue $\mathrm{K}^{+}$were seen only with epinephrine and were inconsistent. Changes in VFT thus correlated with changes in tissue cAMP, but not with changes in high energy phosphate compounds. 
The exact correlation of changes in tissue cAMP with alterations in vulnerability was particularly evident when the concentration-response curve for VFT to epinephrine was displaced to the right by atenolol. The VFT was not reduced until an elevation of tissue cAMP occurred as the competitive blockade was overcome by sufficiently high concentrations of epinephrine. Divergence of antagonism by atenolol for VFT and coronary flow could be shown; at an epinephrine concentration of $10 \mu \mathrm{mol} /$ liter the $78 \%$ decrease in VFT was accompanied by a $250 \%$ increase in tissue cAMP, but coronary flow remained unchanged from the value obtained in control hearts. Changes in tissue cAMP were therefore accompanied by changes in VFT, but not by changes in coronary flow. In the presence of extremely high tissue concentrations of cAMP spontaneous arrhythmias including ventricular fibrillation could be demonstrated and VF induced by electrical stimulation became persistent and refractory to defibrillation in the presence of DBcAMP, theophylline and epinephrine administration.

Satisfaction of the criteria of Sutherland and Robison (17) for cAMP action. The data presented link intracellular cAMP concentrations with arrhythmogenicity. The criteria suggested by these authors for mediation of an action by cAMP are fulfilled: (a) administration of DBcAMP increases ventricular vulnerability by lowering VFT and increasing vulnerable period duration. (b) Phosphodiesterase inhibition with theophylline produced the same effect while causing a demonstrable increase in tissue cAMP. (c) Stimulation with epinephrine increases vulnerability; this effect is competitively inhibited by blockade of the $\beta$-receptor, and is related to an increase in tissue cAMP. $(d)$ The occurrence of spontaneous VF in these rat hearts coincided with very high tissue levels of cAMP; also in the baboon with coronary artery ligation the occurrence of spontaneous VF could be related to high levels of tissue cAMP in the ischemic myocardium (8).

Certain aspects are at present still not fully explained. The ultimate mechanisms whereby cAMP exerts its action on vulnerability may be complex, may involve several factors and still remain conjectural. Small increases in tissue cAMP of up to $20 \%$ of base-line tissue values were often not associated with a reduction in VFT; however, a decrease in VFT invariably accompanied larger increases in tissue cAMP. A critical intracellular level of cAMP may therefore be required before VFT decreases or other factors (e.g. cyclic guanosine 5'-phosphoric acid, electrolyte alterations) may in addition be involved and, with small increases in concentrations of tissue cAMP, may override the VFT-lowering action of intracellular cAMP.
Relevance of these findings. The establishment of regional myocardial ischemia is followed by early and rapid release of catecholamines, mainly epinephrine which can be related to the development of ventricular arrhythmias (4). Local stimulation of myocardial tissue by epinephrine could permit a rapid increase in tissue cAMP (18) and account for the accumulation of this nucleotide in the myocardium involved by ischemia (19). In baboons ligation of a coronary artery is followed by a high incidence of early spontaneous $\mathrm{VF}$, the onset of which has been related to an elevation of tissue cAMP in the infarcting myocardium (8). It has recently been shown, that increased local adrenergic activity measured in terms of tissue cAMP content in the myocardium of the cat with coronary artery ligation, could be documented during the occurrence of ventricular arrhythmias, including ventricular fibrillation (20). In their study Corr et al. (20) found a marked increase of tissue cAMP as early as $2.5 \mathrm{~min}$ after coronary occlusion in cats that went on to develop VF.

A rapid reduction of VFT follows the creation of regional myocardial ischemia in the intact dog (1-3, $21)$. An increase in tissue cAMP could, by the findings of the present study, provide one of the possible mechanisms for this observed reduction in VFT, the consequent increase in vulnerability, and the occurrence of $\mathrm{VF}$ in this early phase of experimental myocardial infarction.

The early reduction in ventricular vulnerability can be prevented by the $\beta$-adrenergic agent, propranolol (6), and by the membrane stabilizing antiarrhythmic agent, lidocaine, provided adequate circulatory levels of lidocaine are obtained (22). Dogs with coronary artery ligation are effectively prevented from developing VF by $\beta$-adrenergic blocking agents (23). The protective effect of these agents is mediated by the $\beta$-receptor blocking action rather than by membrane stabilization (24). Although our studies were performed in the absence of myocardial ischemia, they nevertheless relate the protective action of a $\beta$-adrenergic blocking agent on vulnerability directly to the inhibition of an epinephrine-induced rise in tissue cAMP.

Possible mechanisms whereby cAMP alters vulnerability. Mechanisms whereby intracellular cAMP might operate to predispose arrhythmias can be visualized. The ionic currents associated with the plateau of the cardiac action potential are influenced by changes in intracellular cAMP levels (25). The slow inward $\mathrm{Ca}^{2+}$-dependent current is stimulated by both catecholamines and by DBCAMP (26); slow responses can therefore be induced in cells of the ventricular myocardium by catecholamines by increasing cAMP production (and which can be prevented by propranolol), by methylxanthines which inhibit phos- 
phodiesterase and cAMP breakdown (not inhibited by propranolol) and by DBcAMP as shown by Schneider and Sperelakis (27). The latter authors suggest that the free intracellular cAMP concentration plays a primary role in the mediation of slow channel induction and the elicitation of slow responses. Tissue cAMP levels correlate closely with membrane permeability to $\mathrm{Ca}^{2+}$ ions and with the quantitative aspects of slow $\mathrm{Ca}^{2+}$-dependent currents; consequently Watanabe and Besch (28) suggest that tissue cAMP acts as a modulator of these slow channels. Slow responses are believed to be involved in the initiation and perpetuation of re-entrant ventricular arrhythmias (29).

Clinical implications. In the clinical situation, evidence is accumulating for a protective influence of the $\beta$-adrenergic blocking agents against the development of sudden death in acute myocardial infarction (30-32) and a possible therapeutic role for these agents is envisaged in the management of the early phase of myocardial infarction, in which lidocaine-like agents have been disappointing according to some researchers (33). A sustained state of increased vulnerability to fibrillation has been postulated for the propensity of patients with early myocardial ischemia to develop recurrent episodes of fibrillation (34). The present study links intracellular cAMP to changes in the VFT and consequently to vulnerability in rat hearts, and serves to provide a basis for the further exploration for the clinical use of the $\beta$-adrenergic blocking agents in the early phase of acute myocardial infarction, a situation that remains as a considerable therapeutic challenge.

\section{ACKNOWLEDGMENTS}

We thank Professor S. J. Saunders for encouragement and facilities, the Ethical Drug Association Foundation for partial support of Dr. Podzuweit, and Dr. D. Fitzgerald and Dr. H. Tucker of Imperial Chemical Industries, for supplies of atenolol.

These studies were supported by grants from the Medical Research Council of South Africa and the Chris Barnard Fund for Heart Disease and Organ Transplantation.

\section{REFERENCES}

1. Han, J. 1969. Ventricular vulnerability during acute coronary occlusion. Am. J. Cardiol. 24: 857-864.

2. Axelrod, P. J., R. L. Verrier, and B. Lown. 1975. Vulnerability to ventricular fibrillation during acute coronary arterial occlusion and release. Am. J. Cardiol. 36: 776781 .

3. Meesmann, W., H. Gülker, B., Krämer, and K. Stephan. 1976. Time course of changes in ventricular fibrillation threshold in myocardial infarction: characteristics of acute and slow occlusion with respect to the collateral vessels of the heart. Cardiovasc. Res. 10: 466-473.

4. Ceremuzynski, L., J. Staszewska-Barczak, and K. Herbaczynska-Cedro. 1969. Cardiac rhythm disturbances and the release of catecholamines after acute coronary occlusion in dogs. Cardiovasc. Res. 3: 190-197.

5. Jewitt, D. E., D. Reid, M. Thomas, C. J. Mercer, C. Valori, and J. P. Shillingford. 1969. Free noradrenaline and adrenaline excretion in relation to the development of cardiac arrhythmias and heart failure in patients with acute myocardial infarction. Lancet. I: 635-641.

6. Corbalan, R., R. L. Verrier, and B. Lown. 1976. Differing mechanisms for ventricular vulnerability during coronary artery occlusion and release. Am. Heart J. 92: 223-230.

7. Schaal, S. F., A. G. Wallace, and W. C. Sealy. 1969. Protective influence of cardiac denervation against arrhythmias of myocardial infarction. Cardiovasc. Res. 3: 241-244.

8. Podzuweit, T., A. J. Dalby, G. W. Cherry, and L. H. Opie. 1977. Cyclic AMP levels in ischaemic and nonischaemic myocardium following coronary artery ligation. J. Mol. Cell. Cardiol. In press.

9. Lubbe, W. F., O. L. Bricknell, T. Podzuweit, and L. H. Opie. 1976. Cyclic AMP as a determinant of vulnerability to ventricular fibrillation in the isolated rat heart. Cardiovasc. Res. 10: 697-702.

10. Podzuweit, T., W. F. Lubbe, and L. H. Opie. 1976. Cyclic adenosine monophosphate, ventricular fibrillation and antiarrhythmic drugs. Lancet. I: 341-342.

11. Lubbe, W. F., O. L. Bricknell, and C. Marzagao. 1975. Ventricular fibrillation threshold and vulnerable period in the isolated perfused rat heart. Cardiovasc. Res. 9: 613-620.

12. Wollenberger, A., O. Rustau, and G. Schoffa. 1960. Eine einfache Technik der extrem schnellen Abkühlung gröberer gewebestücke. Pflügers Archiv. Gesamte, Physiol. Menschen. Tiere. 270: 399-412.

13. Brown, B. L., J. D. M. Albano, R. P. Ekins, A. M. Sgherzi, and W. Tampion. 1971. A simple and sensitive saturation assay method for the measurement of adenosine 3'5'-cyclic-monophosphate. Biochem. J. 121: $561-562$.

14. Opie, L. H., K. R. L. Mansford, and P. Owen. 1971. Effects of increased heart work on glycolysis and adenine nucleotides in the perfused heart of normal and diabetic rats. Biochem. J. 124: 475-490.

15. Posternak, T., E. W. Sutherland, and W. F. Henion. 1962. Derivatives of cyclic 3',5'-adenosine monophosphate. Biochim. Biophys. Acta. 65: 558-560.

16. Barrett, A. M., J. Carter, J. D. Fitzgerald, R. Hull, and D. Le Count. 1973. A new type of cardioselective adrenoceptive blocking drug. Br. J. Pharmacol. 47: 340. (Abstr.)

17. Sutherland, E. W. and G. A. Robison. 1969. The role of cyclic $3^{\prime}, 5^{\prime}$-AMP in responses to catecholamines and other hormones. Pharm. Rev. 18: 145-161.

18. Cheung, W. Y., and J. R. Williamson. 1965. Kinetics of cyclic adenosine monophosphate changes in rat heart following epinephrine administration. Nature (Lond.). 207: 979-981.

19. Wollenberger, A., E. G. Krause, and G. Heler. 1969. Stimulation of $3^{\prime} 5^{\prime}$ cyclic AMP formation in dog myocardium following arrest of blood flow. Biochem. Biophys. Res. Commun. 36: 664-670.

20. Corr, P. B., F. X. Witkowski, and B. E. Sobel. 1977. Increased adrenergic tone in ischemic myocardium underlying ventricular fibrillation. Clin. Res. 25: 454A. (Abstr.)

21. Burgess, M. J., J. A. Abildskov, K. Millar, J. S. Geddes, and L. S. Green. 1971. Time-course of vulnerability to fibrillation after experimental coronary occlusion. Am.J. Cardiol. 27: 617-621. 
22. Borer, J. S., L. A. Harrison, K. M. Kent, R. Levy, R. E. Goldstein, and S. E. Epstein. 1976. Beneficial effect of lidocaine on ventricular electrical stability and spontaneous ventricular fibrillation during experimental myocardial infarction. Am. J. Cardiol. 37: 860-863.

23. Pentecost, B. L., and W. G. Austen. 1966. Beta-adrenergic blockade in experimental myocardial infarction. Am. Heart J. 72: 791-796.

24. Khan, M. I., J. T. Hamilton, and G. W. Manning. 1972. Protective effect of beta-adrenoceptor blockade in experimental coronary occlusion in conscious dogs. Am. J. Cardiol. 30: 832-837.

25. Tsien, R. W. 1973. Adrenalin-like effects of intracellular iontophoresis of cyclic AMP in cardiac Purkinje fibres. Nat. New Biol. 245: 120-122.

26. Reuter, J. 1974. Localization of beta adrenergic receptors, and effects of noradrenaline and cyclic nucleotides on action potentials, ionic currents and tension in mammalian cardiac muscle. J. Physiol. (Lond). 242: 429-451.

27. Schneider, J. A., and N. Sperelakis. 1975. Slow $\mathrm{Ca}^{2+}$ and $\mathrm{Na}^{+}$responses induced by isoproterenol and methylxanthines in isolated perfused guinea pig hearts exposed to elevated K+ . J. Mol. Cell. Cardiol. 7: 249-273.

28. Watanabe, A. M., and H. R. Besch. 1974. Cyclic adeno- sine monophosphate modulation of slow calcium influx channels in guinea-pig hearts. Circ. Res. 35: 316-324.

29. Cranefield, P. 1975. In The conduction of the cardiac impulse - the slow response and cardiac arrhythmias. Futura Publishing Co., Inc., Mt. Kisco, N. Y. 294-313.

30. Wilhelmsson, C., J. A. Vedin, L. Wilhelmsen, G. Tibblin, and L. Werkö. 1974. Reduction in sudden deaths after myocardial infarction by treatment with alprenolol. Lancet. II: $1157-1160$.

31. Fox, K. M., M. P. Chopra, R. W. Portal, and C. P. Aber. 1975. Long-term beta blockade: possible protection from myocardial infarction. Br. Med. J. 1: 117-119.

32. Stewart, I. McD. G. 1976. Compared incidence of first myocardial infarction in hypertensive patients under treatment containing propranolol or excluding $\beta$-receptor blockade. Clin. Sci. Mol. Med. 51: 509s-51ls.

33. Darby, S., M. A. Bennett, J. C. Cruickshank, and B. L. Pentecost. 1972. Trial of combined intramuscular and intravenous lignocaine in prophylasis of ventricular tachyarrhythmias. Lancet. I: 817-819.

34. Schaffer, W. A., and L. A. Cobb. 1975. Recurrent ventricular fibrillation and modes of death in survivors of out-of-hospital ventricular fibrillation. N. Engl. J. Med. 293: 259-262 